Western University

Scholarship@Western

Philosophy Publications

Philosophy Department

$11-2007$

\title{
Donating Fresh Versus Frozen Embryos to Stem Cell Research: in whose interests?
}

Carolyn McLeod

Western University, cmcleod2@uwo.ca

Françoise Baylis

Western University

Follow this and additional works at: https://ir.lib.uwo.ca/philosophypub

Part of the Philosophy Commons

Citation of this paper:

McLeod, Carolyn and Baylis, Françoise, "Donating Fresh Versus Frozen Embryos to Stem Cell Research: in whose interests?" (2007).

Philosophy Publications. 476.

https://ir.lib.uwo.ca/philosophypub/476 


\section{DONATING FRESH VERSUS FROZEN EMBRYOS TO STEM CELL RESEARCH: \\ IN WHOSE INTERESTS?}

\section{CAROLYN MCLEOD AND FRANÇOISE BAYLIS}

In countries that limit human embryo research to embryos in excess of clinical need, ${ }^{1}$ there is considerable controversy about the use of fresh versus frozen-thawed embryos for the derivation of embryonic stem cell lines. ${ }^{2}$ On the one hand, there are those who insist that all embryos

${ }^{1}$ These countries include Canada, China, Germany, Iceland, and Italy. See Canada. Assisted Human Reproduction Act, S.C. 2004, c. 2; China, Hong Kong, The Human Reproductive Technology Ordinance, An Ordinance no. 47, Available at: http://www.hklii.org.hk/hk/legis/ord/561 [Accessed on 20 Dec 2008]; Germany. Act Ensuring Protection of Embryos in Connection with the Importation and Utilization of Human Embryonic Stem Cells - Stem Cell Act - of 28 June 2002. Available at: http://www.bmj.bund.de/files//1146/Stammzellgesetz\%20englisch.pdf [Accessed on 20 Dec 2008]; Iceland. Regulation No. 568/1997 on Artificial Fertilization, Available at: http://eng.heilbrigdisraduneyti.is/laws-andregulations/nr/686 [Accessed on Dec 20 2008]; and G. Benagiano \& L. Gianaroli. The New Italian IVF Legislation. Repro BioMed Online 2004; 9, 2: 117-125. Available at: http://www.rbmonline.com/4DCGI/Article/Detail?38\%091\%09=\%201376\%09 [Accessed 20 Dec 2008].

${ }^{2}$ On the controversy, see for example, Canada. The Standing Senate Committee on Social Affairs, Science and Technology. 2007. Ninth Report of the Committee. Available at: http://www.parl.gc.ca/39/1/parlbus/commbus/senate/com-e/soci-e/rep-e/rep09feb07-e.htm 
deemed suitable for transfer to a woman's uterus should be transferred or frozen for later transfer. On the other hand, there are those who want women to donate (some of) their fresh embryos for stem cell research instead of freezing them or discarding them. Among the latter are stem cell scientists who have tried to persuade (and some have succeeded in persuading) in vitro fertilization (IVF) physicians to have their patients donate to research fresh embryos in excess of the maximum recommended for transfer in a single IVF cycle. ${ }^{3}$

People who want women in fertility treatment to donate their fresh embryos to stem cell research tend to be unclear, however, about what kinds of fresh embryos they have in mind. They could mean fresh embryos deemed unsuitable for transfer for morphological, biological or genetic reasons ${ }^{4}$ : that is, embryos that are "unhealthy" for these reasons. ${ }^{5}$ Such a claim would [Accessed 20 Dec 2008]; and Canadian Institutes of Health Research. 2007. 11th Meeting of the Stem Cell Oversight Committee (SCOC). Available at: http://www.cihr-irsc.gc.ca/e/33704.html [Accessed 20 Dec 2008].

${ }^{3}$ In practice, the maximum varies from country to country, from clinic to clinic, and from patient to patient (based on age, reason for treatment, number of previous cycles, etc.). See for example, Joint SOGC-CFAS (Society for Obstetricians and Gynaecologists of Canada-Canadian Fertility and Andrology Society) Guideline. Guidelines for the Number of Embryos to Transfer Following In Vitro Fertilization. J Obstet Gynaecol Can, 2006; 28, 9:803-04.

${ }^{4}$ F. Baylis. Embryological Viability. Am J Bio 2005; 5, 6: 17-18; K. Elder. 2005. Routine Gamete Handling: Oocyte Collection and Embryo Culture. In In Vitro Fertilization and Assisted Reproduction. P.R. Brinsden, ed. London, UK: Taylor \& Francis. ch. 15: 287-307; L. Scott. 2003. Classification of Pronuclei and Polarity of the Zygote: Correlations with Outcome. In $A$ Color Atlas for Human Assisted Reproduction: Laboratory and Clinical Insights. P. Patrizio, M. 
certainly be consistent with statements offered in defense of fresh embryo donation: 'Those embryos which have been tested positive for illness will never be used for reproductive purposes, nor will they be frozen.... They are, however, very valuable for research;' ${ }^{6}$ and ' $[t]$ here are embryos going down the drain all the time. It's a biological waste'. ${ }^{7}$ But in terms of the value for research of fresh embryos unsuitable for transfer (for morphological reasons, at least), available evidence suggests that these embryos are less efficient than frozen-thawed embryos in deriving embryonic stem cell lines. ${ }^{8}$ Research by Sjögren and colleagues involving women in IVF who donated fresh and frozen embryos to stem cell research found that it was better to use frozenthawed rather than fresh embryos. Those who favour fresh embryo donation tend to ignore or

Tucker, V. Guelman, eds. Lippincott Williams \& Wilkins. ch. 5: 71-88; and Nisker and Mykitiuk, "Biomedical Determinants of the 'Health' of Embryos," chapter ??.

${ }^{5}$ They have poor biomedical health. See Nisker and Mykitiuk, chapter ??.

${ }^{6}$ Andras Nagy, first Canadian stem cell scientist to derive human embryonic stem cell lines from fresh embryos, quoted in Flawed Embryos Sought for Research, Vancouver Sun, cited in: 2005. University of Toronto News Digest 6 Oct. Available at: http://www.news.utoronto.ca/inthenews/archive/2005_10_06.html [Accessed on 20 Dec 2008]. ${ }^{7}$ A. Nagy, quoted in M. Munro. 2006. Controversial Stem Cell Project Gets Green Light: Canadian Agency Authorizes use of 'Fresh' Embryos for First Time. The Ottawa Citizen. 27 June. Available at: http://www.canada.com/ottawacitizen/story.html?id=b46a30c6-c67e-4c14ace3-fd8f269e548b\&k=86316\&p=2 [Accessed on 20 Dec 2008].

${ }^{8}$ A. Sjögren et al. Human Blastocysts for the Development of Embryonic Stem Cells. Reprod Biomed Online 2004; 9: 326-9. This is the only study we know of that compares the efficiency of fresh versus frozen-thawed embryos for stem cell derivation. 
dismiss this finding, however; and, without supporting evidence, insist that it is better to derive human embryonic stem cell lines from fresh embryos. ${ }^{9}$ Their insistence leads us to believe that by 'fresh embryos,' they actually mean to include both embryos deemed suitable for transfer as well as embryos deemed unsuitable for transfer (which would be consistent with policy statements permitting embryonic stem cell research involving fresh embryos of either type). ${ }^{10}$

${ }^{9}$ H. Greely. Moving Human Embryonic Stem Cells from Legislature to Lab: Remaining Legal and Ethical Questions. PLoS Med 2006; 3, 5, e143: 0571-0575, at 0572; K. Rook. 2005. Canadian Stem-Cell Research Wins Approval. The Globe and Mail 9 June: A13 Available at: http://www.theglobeandmail.com/servlet/Page/document/v5/content/subscribe?user_URL=http:// www.theglobeandmail.com\%2Fservlet\%2FArticleNews\%2FTPStory\%2FLAC\%2F20050609\%2 FSTEMCELLS09\%2FTPHealth\%2F\&ord=31057750\&brand=theglobeandmail\&force_login=tru e [Accessed on 20 Dec 2008]; M. Munro. 2006. 'Fresh' Embryos OK for Research. National Post 27 June. Available at: http://www.canada.com/nationalpost/news/story.html?id=0c72d357626d-4fac-9446-6b8d62e4d054\&k=59768\&p=2 [Accessed on 20 Dec 2008]; M. Munro. 2006. Ban Fresh Embryo Donations, Ethics Adviser Insists. Vancouver Sun 28 June. Available at: http://www.canada.com/vancouversun/news/story.html?id=47687071-4a17-4e10-b708$\underline{820 \mathrm{e} 6 \mathrm{dbdf} 81 \mathrm{a} \& \mathrm{k}=82919}$ [Accessed on 20 Dec 2008].

${ }^{10}$ See for example, Canadian Institutes of Health Research. 2007. Updated Guidelines for Human Pluripotent Stem Cell Research. 29 June. Available at: http://www.irsc.gc.ca/e/34460.html [Accessed on 20 Dec 2008]. Permitted research includes: 'Research to derive and study human embryonic stem (ES) cell lines or other cell lines of a pluripotent nature from human embryos, provided that: The embryos used, whether fresh or 
But if fresh embryos suitable for transfer are what advocates of fresh embryo donation have in mind, then they equivocate on the use of the term 'fresh embryos' (since these are not the embryos that are going down the drain), and more importantly, their proposals are immensely worrisome, ethically speaking, because donating fresh embryos suitable for transfer is contrary to the interests of female IVF patients.

In this paper, we explain why donating to stem cell research specifically, and to embryo research more generally, fresh embryos suitable for transfer (i.e., "healthy" fresh embryos) is not in the self-interests of female IVF patients. ${ }^{11}$ Next, we consider the other-regarding interests of these patients and conclude that while fresh embryo donation may serve those interests, it does so at unnecessary cost to patients' self-interests. Lastly, we review some of the potential barriers to the autonomous donation of fresh embryos to research and highlight the risk that female IVF patients invited to donate their excess fresh embryos to research will misunderstand key aspects of the donation decision, be coerced to donate, or be exploited in the consent process. For the

frozen, were originally created for reproductive purposes and are no longer required for such purposes' (emphasis added).

${ }^{11}$ J. Nisker \& A. White. The CMA Code of Ethics and the Donation of Fresh Embryos for Stem Cell Research. Can Med Assoc J 2005; 173, 6: 621-622, at 621; F. Baylis \& N. Ram. Eligibility of Cryopreserved Human Embryos for Research in Canada. J Obstet Gynaecol Can 2005; 27, 10 : 949-955, at 950; F. Baylis \& C. McInnes. Women at risk: Embryonic and fetal stem cell research in Canada. McGill Health Law Publication 2007: 1, 53-67 [Online]. Available: http://mjlh.mcgill.ca/texts/volume1/pdf/baylis-mcinnes.pdf [Accessed on 20 Dec 2008]; and F. Baylis et al. 2007. Nothing Extreme about Protecting Fresh Embryos. The Globe and Mail 16 Jan: A15. 
purposes of this discussion, we focus on female IVF patients (hereafter patients), because the implications of fresh embryo donation are more serious for them than for male IVF patients.

On the basis of our analysis, we conclude that patients should not be asked to donate to stem cell research fresh embryos suitable for transfer, even if (at some future date) there was overwhelming evidence that these embryos were highly efficient in establishing stem cell lines. In our view, such donation should be prohibited as a matter of sound public policy because allowing it would ultimately contribute to women's continued oppression. Thus, social justice demands no less than a total ban on the research use of fresh embryos from IVF patients, when these embryos have been deemed suitable for transfer (hereafter 'fresh embryos,' unless otherwise noted). ${ }^{12}$

\section{RELEVANT INTERESTS OF WOMEN UNDERGOING IVF}

It is important for the physical and psychological health of women undergoing IVF to avoid ovarian stimulation and egg retrieval, where possible. Doing so is not possible in the first cycle of IVF, but it may be possible thereafter if there are excess embryos and if these embryos are frozen for later possible use. Hence, most IVF clinics recommend freezing excess embryos. But now, in Canada - where the law prohibits creating 'an in vitro embryo for any purpose other than creating a human being or improving or providing instruction in assisted reproduction

\footnotetext{
12 Notice that our objection is not to all human embryo research involving embryos in excess of clinical need (or in other words, "spare" embryos; see Scully et al, chapter ??). We have no principled objection to the research use of either frozen embryos or fresh embryos deemed unsuitable for transfer.
} 
procedures ${ }^{13}$ - stem cell researchers are asking IVF physicians to invite their patients to donate their fresh embryos to research, instead of freezing them for later reproductive use. ${ }^{14}$ Some IVF physicians have acquiesced. But others have declined: 'It's so controversial. I'm not going to touch it'. ${ }^{15}$ We think that IVF physicians should decline such requests, because accepting them would require that they act in a manner inconsistent with their obligation to protect and promote patients' interests.

\section{Self-interests}

Current live birth rates with IVF are such that any one IVF cycle probably will not result in a live birth (as live birth rates per cycle are less than $50 \%$, and often substantially less than $50 \%$ ). Thus, patients determined to reproduce using IVF likely will need a subsequent cycle, and

${ }^{13}$ Assisted Human Reproduction Act, S.C. 2004, c.2. s.5 (1)(b). Available at: http://www.canlii.org/ca/sta/a-13.4/ [Accessed on 20 Dec 2008]

${ }^{14}$ Rook, op. cit. note 8; H. Branswell. 2005. Toronto Institute Develops Canada's First Two Embryonic Stem Cell Lines. Canadian Press 8 June; Munro, op. cit. note 6. Controversial Stem Cell Project; Munro, op. cit. note 8. 'Fresh' Embryos OK.

${ }^{15}$ Dr. Cal Greene of the Calgary-based Regional Fertility Program quoted in P.J. Smith. 2006. Alberta Scientist begins Stem-Cell Extraction on Human Embryos. LifeSiteNews.com: 10 August. Available at: http://www.lifesite.net/ldn/2006/aug/06080902.html [Accessed on 20 Dec 2008]. Similar comments were made to us by clinicians at the $52^{\text {nd }}$ annual meeting of the Canadian Fertility and Andrology Society (CFAS) in Ottawa, Canada (Nov 2006), where we presented the poster, 'The Ethics of Inviting Female IVF Patients to Donate Fresh Embryos to Stem Cell Research.' Available at http://www.noveltechethics.ca/site_genetic.php?page=209 [Accessed on 20 Dec 2008] 
it is common practice for this cycle to involve the transfer of frozen-thawed embryos from a prior cycle.

Donating fresh embryos to research, instead of freezing them for use in a future IVF cycle, is contrary to the self-interests of most patients for at least five reasons: first, donating fresh embryos can decrease the chance of pregnancy and childbearing; second, it can increase the number of risky or painful procedures that women must undergo; third, it can increase the psychological stress experienced by women as a result of IVF; fourth, it can increase the social disruption that IVF causes; and fifth, it can increase the financial burden of fertility treatment. Let us elaborate on each of these reasons.

First, donating fresh embryos to research can decrease women's chances of pregnancy and childbearing, ${ }^{16}$ especially for women who become unwilling or unable to consent to further ovarian stimulation and egg retrieval and who have no (more) frozen embryos available for thawing and transfer because of a prior decision to donate fresh embryos to research. Any woman could develop an unwillingness or inability to do further ovarian stimulation and egg retrieval, because of how burdensome - physically, psychologically, and socially — these processes tend to be for women (as explained below). Also, any woman could become unwilling or unable to do more ovarian stimulation and egg retrieval because of financial or other (e.g., health) reasons. Since these are possibilities for all women, all women who give away fresh embryos that they could freeze for later reproductive use lessen their chances of reproducing and thereby possibly thwart their goal of childbearing.

Second, donating fresh embryos to research means that women who undertake another IVF cycle may again have to accept the physical risks and pain involved in ovarian stimulation

\footnotetext{
${ }^{16}$ Nisker \& White, op. cit. note 10, p. 621.
} 
and egg retrieval, which could be avoided with an IVF cycle using frozen-thawed embryos. There are significant physical risks associated with ovarian stimulation. The short-term health risk is that of ovarian hyperstimulation syndrome (OHSS). Mild forms of OHSS involve 'transient lower abdominal discomfort, mild nausea, vomiting, diarrhea, and abdominal distention (observed in up to a third of superovulation cycles) ${ }^{\prime} \cdot{ }^{17}$ More serious forms of OHSS entail 'rapid weight gain, tense ascites, hemodynamic instability (orthostatic hypotension, tachycardia), respiratory difficulty, progressive oliguria and laboratory abnormalities. Lifethreatening complications of OHSS include renal failure, adult respiratory distress syndrome (ARDS), hemorrhage from ovarian rupture, and thromboembolism'. ${ }^{18}$ It was reported at the 2006 meeting of the European Society for Human Reproduction and Embryology that six women had died of OHSS. ${ }^{19}$ The long-term risks of ovarian stimulation are less well documented. Two

${ }^{17}$ Ovarian Hyperstimulation Syndrome, National Guidelines Clearinghouse (a comprehensive database of evidence-based clinical practice guidelines and related documents). Available at: http://www.guideline.gov/summary/summary.aspx?doc_id=4845 [Accessed on 20 Dec 2008]. Information based on: Practice Committee of the American Society of Reproductive Medicine. Ovarian Hyperstimulation Syndrome. Fertil Steril 2003; 80, 5: 1309. See also A. Delvigne \& S. Rozenberg. Epidemiology and Prevention of Ovarian Hyperstimulation Syndrome (OHSS): a review. Hum Reprod Update 2002; 8: 559-577.

18 Ibid.

${ }^{19}$ H. Pearson. Health Effects of Egg Donation may take Decades to Emerge. News@,Nature.com 9 August 2006, available at:

http://www.nature.com/nature/journal/v442/n7103/full/442607a.html [Accessed 20 Dec 2008] 
studies, however, suggest a link between ovarian stimulation and ovarian cancer. ${ }^{20}$ In addition, egg retrieval can be very painful and is therefore feared by many women. ${ }^{21}$ The short- and longterm risks of ovarian stimulation as well as the pain and fear of egg retrieval can all be avoided by transferring frozen-thawed embryos.

Third, donating fresh embryos to research could mean more psychological stress for patients than they would otherwise experience. Women in general report higher levels of psychological stress from IVF than men, presumably because they have more invested in the outcome (including their self-image, their time, and their physical well-being) ${ }^{22}$ Arguably, an IVF cycle that includes ovarian stimulation and egg retrieval is more stressful psychologically for women than a cycle using frozen-thawed embryos. The added effort and risk involved in a cycle using fresh embryos can make it all the more difficult to await the outcome of treatment, knowing that if it does not work, they will have done it all for nothing.

A fourth reason why fresh embryo donation can violate women's interests is that typically a IVF cycle that involves ovarian stimulation and egg retrieval is more socially

${ }^{20}$ A.S. Whittemore et al. Characteristics Relating to Ovarian Cancer Risk: Collaborative Analysis of 12 US Case-control Studies. II Invasive Epithelial Ovarian Cancers in White Women. Am J Epidemiol 1996; 136, 10: 1184; and M.A. Rossing et al. Ovarian Tumors in a Cohort of Infertile Women. NEJM 1994; 331, 12: 771; L.A. Brinton et al. Ovarian Cancer Risk After the Use of Ovulation-Stimulating Drugs. Obstet Gynecol 2004; 103: 1194-1203.

${ }^{21}$ A. Eugster \& A.J.J.M. Vingerhoets. Psychological Aspects of In vitro Fertilization: A Review. Soc Sci Med 1999; 48: 575-589.

${ }^{22}$ A.L. Greil. Infertility and Psychological Distress: A Critical Review of the Literature. Soc Sci Med 1997; 45: 1697-704. 
disruptive than a cycle using frozen-thawed embryos because of the daily blood tests and routine ultrasounds involved. The blood tests typically occur in the early morning (around 7am) and if the women also need an ultrasound that day, then they may have to wait around or make a return visit. For women who work outside of the home or who have children at home to care for, frequent early morning blood tests and ultrasounds are difficult to schedule, especially for those women who have to travel great distances to get to these appointments.

Lastly, donating fresh embryos to research is problematic insofar as it is contrary to the financial interests of many patients. An IVF cycle that involves ovarian stimulation and egg retrieval is more expensive than an IVF cycle using frozen-thawed embryos, even when the additional cost of embryo freezing is taken into account. With a frozen-thawed embryo cycle, one typically avoids the expense of sperm collection, sperm-washing, ovarian stimulation, and egg retrieval, as well as associated clinic and physician charges. One study estimates the cost saving with frozen-thawed embryo transfer at between $55-75 \%$ as compared with other assisted reproductive procedures. ${ }^{23}$

Thus, for many patients, donating fresh embryos to research is not in their self-interests. It is not in their reproductive self-interest; not in their interest in maintaining their overall physical and mental health; not in their career or family interests; and likely also not in their financial interests. Overall, for their own sakes, patients are better off freezing their excess fresh

${ }^{23}$ B.J. Van Voorhis et al. The Efficacy and Cost Effectiveness of Embryo Cryopreservation Compared with Other Assisted Reproductive Techniques. Fertil Steril 1995; 64, 3: 647-650. 
embryos, rather than donating them to research. The overwhelming majority of women seem to recognize this fact; rates of embryo freezing are as high as $99 \% .^{24}$

The only possible caveat here is that donating excess fresh embryos to stem cell research may be in patients' self-interests if they are (or believe themselves to be) at risk for one of the medical problems for which stem cell research may lead to effective treatment. We do not explore this possible future self-interest in this section of the paper, not because it is unimportant, but because at best it would be secondary to the primary self-interest in initiating a pregnancy. Our analysis of this secondary self-interest parallels our analysis below of other-regarding interests (which we also consider secondary to the primary self-interest in initiating a pregnancy).

Since fresh embryo donation to research goes against the self-interests of most women undergoing IVF, it is worth asking why stem cell researchers would expect patients to donate fresh embryos in sufficient numbers to allow them to undertake the research they are interested in. Perhaps they do not (or choose not to) accept that these embryos have reproductive potential. Or, they expect that fresh embryo donation will cohere with patients' other-regarding interests, and that patients will allow these interests to outweigh or supersede their self-interests. In other words, perhaps stem cell researchers (and IVF physicians) assume that women undergoing IVF will be altruistic and sacrifice their self-interest(s) to help others. But why make this assumption?

\section{Other-regarding interests}

Usually, when people make big sacrifices, they do so for people with whom they have some affinity. In the context of health care that affinity might be shared membership in a 'disease'

\footnotetext{
${ }^{24}$ L. Lornage et al. Six Year Follow-up of Cryopreserved Embryos. Hum Reprod 1995; 10 :
} 2610-2616. 
group. Thus, infertile IVF patients might be willing to make big sacrifices in support of embryo research to treat infertility. But is there any reason why they might be willing to make big sacrifices to support embryonic stem cell research, where the sacrifice would not be for the sake of people who are like them in being infertile, but for the sake of people with any number of medical problems? One possible answer is that some infertile IVF patients have intimate relations with people who have one or more of the medical problems for which stem cell research may lead to effective treatment (e.g., a parent with Parkinson's disease); and these patients might be willing to promote this secondary interest at some cost to their primary interest in achieving a pregnancy. As Harvard stem cell scientist, Kevin Eggan, puts it, 'women who have families that are afflicted with diseases that we study might step forward' ${ }^{25}$ Yet for it to be reasonable for them to step forward, it would have to be true that they could not achieve their secondary interest without cost to their primary interest. And available scientific data does not support this assumption. To be clear on this last point, researchers could develop stem cell therapies using frozen-thawed rather than fresh embryos. There is evidence that human embryonic stem cell lines can be derived from frozen-thawed embryos, ${ }^{26}$ but as yet, there is no evidence that using fresh embryos would be better than using frozen-thawed embryos. Alternatively, researchers could use somatic tissues instead of embryos. In short, available data

${ }^{25}$ R. Waters \& J. Lauerman. Harvard Scientists Try Cloning to Create Stem Cells (Update2). 2006. Bloomberg.com 6 June. Available at: http://www.bloomberg.com/apps/news?pid=newsarchive\&sid=a9obSc92m0Zk [Accessed 20 Dec 2008].

${ }^{26}$ S.P. Park et al. Establishment of Human Embryonic Stem Cell Lines from Frozen-Thawed Blastocysts using STO Cell Feeder Layers. Human Reprod 2004; 19: 676-84. 
does not show that diverting the use of fresh embryos created for reproductive purposes to stem cell research is necessary for the eventual (possible) development of stem cell therapies. It follows that women do not have to risk undermining their primary interest in pregnancy for a secondary interest in promoting embryonic stem cell research.

The upshot of this discussion about women's interests — self- and other-regarding — is that it is perfectly reasonable for women to be self-interested when faced with the option of donating their fresh embryos to stem cell research (where their self-interest demands that they not take this option). Moreover, it is unreasonable for others to expect women to act any differently. Our view is not that altruism in this domain is impossible, or would always be morally unacceptable, but simply that researchers (and IVF physicians) should not expect women to have such otherregarding interests. Nor should they invite them to act against their self-interests.

\section{POSSIBLE BARRIERS TO AUTONOMOUS DONATION}

In response to our claim that fresh embryo donation is contrary to the self- and other-regarding interests of women, some stem cell researchers and IVF physicians might insist that there are patients ready and willing to donate their fresh embryos to stem cell research. For these donations to be fully autonomous, however, they would have to be made with full understanding and without coercion or exploitation. Below, we dispute each of these possibilities.

\section{Misunderstanding}

Misunderstanding that results in mistaken beliefs can thwart autonomous decision making, as happens with: i) patients who mistakenly believe that fresh embryo donation is in their reproductive interests; ii) patients who understand that fresh embryo donation generally is not in the reproductive interests of women in an IVF program, but who mistakenly believe that they are not to be counted among these women because they are in their 'last' cycle of IVF; and iii) 
patients who mistakenly believe that they are obligated to be altruistic and donate their excess fresh embryos to research.

First, consider the group of patients who mistakenly believe that fresh embryo donation serves their reproductive interests, which it does not. Are patients truly at risk of developing such a wildly mistaken belief? We think so, especially since the persons requesting that patients donate fresh embryos to research, or the persons offering patients the opportunity to do so, are physicians or other care providers. (While in some jurisdictions, researchers are responsible for getting consent to donate embryos to specific research projects, typically physicians, or other care providers, make the initial inquiry into whether patients are willing to donate embryos to research.) Patients might believe that physicians would only suggest interventions that would further their reproductive interests, since their purpose in being at the clinic is to promote these interests and the stated goal of the clinic is to help patients succeed in having children. In addition, physicians might be unclear about how different fresh embryo donation is from other options in fertility treatment, insofar as fresh embryo donation does not improve one's chances of reproducing. (Such lack of clarity is possible given how short appointments with physicians can be. ${ }^{27}$ ) Alternatively, patients might have stopped listening to details about 'options' presented by physicians, because of how complex the information often is, and simply decided to accept what their physicians recommend/offer, on the grounds, again, that physicians would only recommend/offer to them whatever could further their reproductive goals. The problems alluded to here are of informational complexity and of undue deference to physicians by patients.

\footnotetext{
${ }^{27}$ M. Malin et al. What Do Women Want? Women's Experiences of Infertility Treatment. Soc
} Sci Med 2001; 53: 123-133. 
To be sure, the same problem of confusing embryo donation with a choice that furthers one's reproductive interests can occur with frozen (not only fresh) embryo donation. But the donation of frozen embryos usually takes place once the women are no longer patients (and may never again be patients), and for this reason the women are less likely to see donation as a positive step toward reproducing. Also, at the time of frozen embryo donation the women are likely at a distance, both physically and psychologically, from their physicians and so they are less likely to be influenced by what their physicians want (or by what they perceive them to want). ${ }^{28}$ Notably, many IVF patients who consent to the future donation of excess frozen embryos to research at the outset of treatment change their mind once they are no longer in active treatment and no longer potentially influenced by what their physicians might want. ${ }^{29}$

Second, consider the group of patients who mistakenly believe that they do not need to freeze excess fresh embryos for later reproductive use because they are done with IVF. This mistaken belief could be the result of them misunderstanding their chances of success with IVF, misunderstanding how psychologically prepared they are or will be for future IVF cycles, or

${ }^{28}$ For this reason, among others, the Ethics Committee of the American Society for Reproductive Medicine (ASRM) recommends that only frozen embryos be used for research. Ethics Committee of the ASRM. Donating Spare Embryos for Embryonic Stem-Cell Research. Fertil Steril 2004; 82, Suppl 1: S224-7 at S226.

${ }^{29}$ S.C. Klock, S. Sheinin \& R.R. Kazer. The Disposition of Unused Frozen Embryos [letter]. NEJM 2001; 345, 1: 69-70; J. Nisker et al. Development and Investigation of a Free and Informed Choice Process for Embryo Donation to Stem Cell Research in Canada. J Obstet Gynaecol Can 2006; 28, 10: 903-908. 
misunderstanding their financial ability to continue with IVF. We address each of these possibilities in turn.

Perhaps the most common reason why a very few patients do not freeze excess fresh embryos for use in subsequent IVF cycles is that they are very confident that IVF will work for them the first time (i.e., result in a pregnancy and a healthy live birth), so they will not need further IVF cycles. ${ }^{30}$ Being over-confident about the success of IVF is common among patients, especially those who are in their first cycle. ${ }^{31}$ Such optimism can function as a kind of coping mechanism. ('I need to believe it is going to work; otherwise why would I be putting myself through all of this?') But IVF does not always (often) work. Failure in a first cycle can make obvious what may not have been obvious before: that IVF is not foolproof or that one may have a serious fertility problem.

Extreme optimism (especially in one's first IVF cycle) could stem from various sources. One source of optimism is clinic staff members, who sometimes express more optimism about treatment than they ought to. ${ }^{32}$ Another source is family members or friends, especially those for whom reproduction was easy and who simply do not understand how the treatment could not work given that everything is timed so perfectly. A third source of optimism is society, which teaches us, especially through secondary school, that the chances of getting pregnant are about as

\footnotetext{
${ }^{30}$ Personal communication between Angela White (research assistant to C. McLeod) and Dr. Valter Feyles, reproductive endocrinologist, London Health Sciences Centre.

${ }^{31}$ V.L. Peddie, E. van Teijlingen \& S. Bhattacharya, S. A Qualitative Study of Women's Decision-making at the End of IVF Treatment. Hum Reprod 2005; 20, 7: 1944-1951. ${ }^{32}$ Ibid.
} 
high as the chances of it raining in the spring.$^{33}$ Society—more specifically the media—also tells us repeatedly of the miracles that reproductive technologies create, thereby distorting the success rates of these technologies. A fourth source of optimism is the women themselves who probably have internalized these social messages, along with other messages that connect womanhood with pregnancy and motherhood. The latter could make it impossible for women even to recognize themselves as women if they were to accept that they had a serious fertility problem. As a consequence, they may not accept this fact and may be overly optimistic about IVF.

No patient can be fully informed about whether her current IVF cycle will be successful and about what her preferences will be in terms of doing another cycle if the current one is unsuccessful. Thus, it is in women's interests to freeze all embryos suitable for transfer for possible future use in a later cycle.

Another reason why some IVF patients may say they are finished with IVF is that they do not feel that they have it in them to do more cycles. (In all likelihood, these are patients who have been through several IVF cycles.) But, of course, these patients could be wrong in thinking that they are done with IVF. Patients can and do change their minds about continuing with IVF, especially if their most recent cycle was 'unexpectedly' unsuccessful. For many patients, giving up on IVF is very difficult. It requires of women that they accept their infertility (which some deny, unjustifiably, even while they are in treatment) ${ }^{34}$ and perhaps their childlessness as well.

${ }^{33}$ The comparison with spring rain comes from V. Hey et al. 1996. Hidden Loss: Miscarriage and Ectopic Pregnancy, $2^{\text {nd }}$ ed. London, UK: Women's Press. They say that society leads us to believe the chances of having a child after getting pregnant are as high as rain in June.

${ }^{34}$ Y. Benjamini, M. Gozlan \& E. Kokia. On the Self-regulation of a Health Threat: Cognitions, Coping, and Emotions among Women undergoing Treatment for Infertility. Cognit Ther Res 
For some women, accepting either or both of these things is tantamount to admitting that they will never attain true womanhood and will never have good lives.

A further reason why some women may believe they are finished with IVF is that they no longer have the money to pursue their reproductive dream. IVF is costly. For some patients one IVF cycle will represent their entire life savings. Other patients may have more disposable income, yet have reached the limit of what they are prepared to invest in their reproductive project. In either case, financial circumstances or beliefs could change, making it possible to proceed with one or more future IVF cycles (each of which would be less costly if there were frozen embryos available for thawing and transfer).

In summary, women could want to donate fresh embryos to research because, for any number of reasons, they mistakenly believe that they are done with IVF and so will not need frozen embryos for future reproductive purposes.

Lastly, patients willing to donate fresh embryos to research could be mistaken in their belief that they are morally obligated to donate. Patients might assume that they ought to donate their excess fresh embryos because doing so would benefit humanity and they are morally obligated to act so as to benefit humanity, even at some risk to themselves. But we know from our previous discussion about altruism that donations of fresh embryos to stem cell research by patients is not the only (or perhaps even the best) way to proceed with this research and patients would be wrong to assume otherwise. Moral philosophy also tells us that whether people are morally required to help others while putting their own well-being at risk is complicated. It is certainly not obvious in the case of IVF treatment that women are obligated to donate fresh

2004; 28, 5: 577-592; O.B.A. van den Akker. Coping, Quality of Life and Psychological Symptoms in Three Groups of Sub-fertile Women. Patient Educ Couns 2005; 57: 183-189. 
embryos that could, if the embryos implanted, put an end to their struggle with infertility, even if the relevant research would inevitably create a breakthrough in stem cell therapy.

Thus, various factors (psychological, social, and financial) can interfere with patients' understanding key aspects of the decision of whether to donate their fresh embryos to research. Failing to see that donation is not connected with reproduction, believing in error that one is truly done with IVF, or wrongly assuming that one is morally required to donate fresh embryos to research can prevent patients from truly knowing whether donation fits with their autonomous desires.

\section{Coercion}

Patients may fully understand everything that is relevant to a decision to donate fresh embryos to stem cell research, and still not choose autonomously because they are coerced. The coercion may be the result of a coercive offer or of a threat of harm. ${ }^{35}$

To be coerced is to be compelled to accept and possibly act upon a proposal (e.g., to donate fresh embryos to stem cell research) on the grounds that failure to do so would worsen one's situation relative to the pre-proposal situation (a non-normative baseline of comparison) or to a situation that is fair (a normative baseline). The proposal—whether intentional or unintentional - alters or influences the will of the person coerced, making her choose differently than she otherwise would, it being rational or necessary for her to do what the coercer wants her to do.

${ }^{35}$ Not everyone agrees that coercion can be the result of an offer rather than a threat, but we find this view persuasive. (See S. Anderson. 2006. Coercion. Stanford Encyclopedia of Philosophy online. E.N. Zalta, ed. Available at http://plato.stanford.edu/entries/coercion/\#CoeOff [Accessed 20 Dec 2008], section 2.4 'Coercive offers?’) 
In practice, the coercer can be an institution or an institutionalized set of social norms rather than an actual person. ${ }^{36}$ Following Ann Cudd, we call such coercion simply, 'institutional coercion.' Sometimes people have trouble identifying institutional coercion because they take the relevant institutions or norms for granted (i.e., as simply the way things are), as many people do, for example, with the institutions of motherhood and heterosexuality. Widespread acceptance of institutionalized norms in no way diminishes their coercive effect, however.

Further, for there to be coercion, the offer or threat need not be real in the sense that the person's circumstances really would improve if she responded to the offer, or worsen if she failed to respond to the threat. The offer or threat need only be credible and compelling to the person for there to be coercion. For example, an offer or threat could be a bluff, yet still have a coercive effect.

Finally, coercion is prima facie wrong because it violates autonomy. People who are coerced do not choose freely, although they may make choices (e.g., the choice to save their skins by complying with a particular threat). ${ }^{37}$

In this paper, we focus on threats of abandonment (i.e. by one's physician or other care providers) and threats of stereotyping, both of which could coerce women to donate fresh embryos for research. These threats most likely stem from social norms and structures, although they could also issue from individuals, most notably physicians (and other care providers) or researchers. Moreover, the threat of being abandoned is perhaps most common, or most severe, when the person who asks whether the patient wants to donate her fresh embryos to stem cell

${ }^{36}$ A. Cudd. Oppression by Choice. J Soc Philos 1994; $25^{\text {th }}$ Anniversary Special Issue: 22-44, at 29.

37 Ibid. 
research is her physician as opposed to a stem cell researcher. But a threat of abandonment could also exist when the request/offer comes from a researcher, because a physician ultimately directs the patient to the researcher, thus indicating to the patient that s/he, the physician, supports what the researcher is doing.

No matter who asks the patient about fresh embryo donation, therefore, the patient might reason that if she does not consent to the donation, then her physician will abandon her as a patient or treat her less well than s/he otherwise would. But why might a patient think that she will be abandoned? We give two possible reasons. 1) She might assume that her physician would not ask her about fresh embryo donation, or direct her to a researcher who would ask her to consent to embryonic stem cell research (or have a nurse or other care provider direct her to such a researcher), if the physician did not believe that donating was a reasonable (possibly even good) thing to do. This assumption would flow from the commonly held view that physicians only have their patients' best interests in mind and at heart. 2) Patients might know that the treatment they are receiving is elective, which suggests that they do not have the same right to it as they do to medically necessary therapies and that their physicians are not under the same obligation to provide it. Also, many patients may not have other physicians to turn to, especially if there is only one fertility clinic in their area. Taken together these thoughts could help to form a strong desire in patients to be compliant with what they take to be the physician's own view, namely, that fresh embryo donation is a reasonable (possibly even good) thing to do. These thoughts also make a threat of abandonment credible, although the threat may not be real. Patients who respond to such a perceived threat in deciding to donate their fresh embryos to research are coerced. 
The threat of abandonment, as we have described it, arises out of social norms and structures. But the behaviour of physicians and other care providers could also enhance (or diminish) this threat. For example, it matters how a physician or other care provider presents a proposal for donating fresh embryos to research, or presents a proposal for the patient to talk with a stem cell researcher who wants to obtain fresh embryos. Does s/he make it sound as though fresh embryo donation is something that patients ought to accept? Further, does the culture of the clinic bolster the perceived threat? For example, if physicians, nurses and other clinic staff tend to expect compliance (and label patients 'non-compliant' or 'problem patients' if they are demanding or questioning), then the perceived (or real) threat of abandonment for refusing a certain option or recommendation may be high.

Stereotyping by physicians or researchers is another potential threat that might compel patients to donate fresh embryos to research. ${ }^{38}$ Like the threat of abandonment, the perception of a stereotype threat here begins with the assumption that the physician, or in this case perhaps the researcher, favours donation because it is a rational, praiseworthy thing to do. On this assumption, women who do not donate are at risk of being labeled 'hormonal,' that is, irrational or overly emotional. The threat of this stereotype is unusually high in fertility treatment because of the hormone medication(s) that women take. In an effort to avoid this stereotype, patients may respond positively to the 'rational' proposal that they donate their fresh embryos to research. Another stereotype that might compel patients to donate fresh embryos to research is that of the selfless woman, dedicated to caring for others. Here, the goal is not to avoid the stereotype, but

\footnotetext{
${ }^{38}$ On stereotype threats, see C. Steele. A Threat in the Air: How Stereotypes Shape Intellectual Identity and Performance. Am Psychol 1997; 52, 6: 613-629.
} 
rather to satisfy it. Patients can achieve this by donating their fresh embryos to research, which shows substantial concern for others.

But why assume that many patients in fertility treatment would perceive themselves to be at serious risk of animating stereotypes, especially with their physician, with whom they presumably have a meaningful relationship, at least compared to what they have with a researcher? Stereotypes prevail more easily in the absence of meaningful relationships. (To illustrate, we often stereotype strangers and cease to do so only once they cease to be strangers to us.) Unfortunately, however, one cannot assume that patients undergoing fertility treatment usually have meaningful relationships with their physician; in fact, there is good reason to believe that in general, these relationships are quite poor. One study in Finland shows that for women who are dissatisfied with fertility treatment, the greatest source of dissatisfaction is their relationship with their physician: s/he did not spend enough time with them, was not empathetic enough, did not understand their particular worries and concerns, etc. ${ }^{39}$ In some cases, the dissatisfaction came from the team approach to fertility treatment, in which patients receive care most of the time from a team of physicians and nurses rather than from one particular physician or nurse. With this approach, patients often do not know who will provide what care when: they may get a different physician every day or every other day that they go in for an ultrasound to monitor their follicle production; and they may get a different nurse every day calling them to tell them their blood test results. The team approach, which is common in fertility clinics, can benefit patients to be sure (e.g. by allowing them to get treatment quicker than they otherwise would); but it also denies patients the ability to have a relationship, of any meaningful sort, with

${ }^{39}$ Malin et al., op. cit. note 26. 
their care providers. Consequently, it enhances the risk for patients of experiencing stereotype threats.

Thus, various social norms (e.g., stereotypes) and social structures (e.g., the team approach) are in place that can coerce patients to donate fresh embryos to stem cell research. We accept that these norms and structures can compromise consent not only for fresh embryo donation, but for other options as well. Yet their coercive force is particularly worrisome in the context of fresh embryo donation, because of how much worse off patients can be as a result of making such a donation.

\section{Exploitation}

Agreements that IVF patients make to donate fresh embryos to stem cell research can be purely coercive. But they can also be exploitative and coercive. With the latter, we have in mind agreements that take unfair advantage of how beholden some patients feel to their IVF physicians and who donate their fresh embryos as a way of giving back to their physicians. These patients may have a strong desire to donate; yet their desire may originate or be influenced by coercive forces in our society (as illustrated below). Coercion can make us go against our immediate desires, as it does in the case of patients who would rather not donate their fresh embryos to research, but who do so anyway to avoid abandonment or stereotyping. Or, coercion can explain, in part or in whole, why we have some of the immediate desires that we do: we were coerced into having them, even though we may not now recognize this fact. The latter sort of coercion, combined with exploitation, is a further potential barrier to women autonomously donating their fresh embryos to stem cell research.

Assuming we already understand coercion, let us explore the meaning of exploitation briefly. Exploitation involves taking unfair advantage of someone. If you are taking unfair 
advantage, then you, the exploiter, must benefit. By contrast, the person you exploit either receives no (net) benefit or some benefit but not what she deserves. In the former case, the exploitation is harmful and in the latter, it is mutually advantageous, that is, relative to a baseline of non-cooperation.$^{40}$ Exploitation that is mutually advantageous is not advantageous to both parties in a way that is fair, as happens, for example, when the person exploited was in a vulnerable position to begin with (e.g., she was oppressed or impoverished), did not deserve to be in this position, and her vulnerability explains why she agrees to cooperate in the first place. While relative to her initial circumstances, she benefits from cooperating with the person who ultimately exploits her, relative to circumstances that are fair, she does not benefit to the degree that she ought to. (Here, the baseline of comparison is a normative baseline.) Rather than getting what she deserves, she gets the scraps offered to her by the person who takes advantage of her vulnerable state.

One further point about exploitation: like coercion, exploitation can be intentional or nonintentional. Out of charity, we assume that exploitation of patients in the context of fresh embryo donation for stem cell research is non-intentional: researchers or physicians who exploit the donors do not intend to take unfair advantage of them, but do so as a result of their interactions. For example, stem cell researchers and some physicians may take unfair advantage of the fact that some patients feel beholden to physicians for treating their infertility (and thus are in a state of moral vulnerability) and see fresh embryo donation as a way to relieve their sense of

${ }^{40}$ A. Wertheimer. 2001. Exploitation. Stanford Encyclopedia of Philosophy online. E.N. Zalta, ed. Available at: http://plato.stanford.edu/entries/exploitation [Accessed 20 Dec 2008]. On exploitation, see also R.J. Sample. 2003. Exploitation: What It Is and Why It's Wrong. Lanham: Rowman \& Littlefield. 
indebtedness. The researchers could be the exploiters - taking unfair advantage of patients who feel beholden — even though the physicians are the ones to whom patients feel beholden.

Why might some patients feel so beholden to IVF physicians that they would be willing to donate fresh embryos to research, and possibly compromise their reproductive future in order to repay the debt that they feel they owe? For some patients, physicians manage to get them government subsidies for their care, or, in rare cases, they pay for the treatment, as one physician did on Mother's Day 2006 for a woman who 'desperately' needed IVF but could not afford it. ${ }^{41}$ Intense feelings of gratitude would be common in these cases. But such feelings could also arise among patients who have to pay for the treatment themselves. They might feel beholden because of a deep desire to get pregnant and a perception of their physician as a saviour to them- that is, someone who will rescue them from an 'empty, childless life.' Some physicians encourage this perception of themselves when they are optimistic with patients about being able to 'cure' them.

Patients who donate fresh embryos out of a sense of indebtedness benefit in being relieved of their perceived debt. But this benefit may not outweigh the harm that they experience (i.e. to their reproductive goals and to their overall physical and mental health), in which case, the agreement to donate would be harmful to them. Alternatively, the agreement could be mutually advantageous, as it is when the benefit of expressing their gratitude outweighs the harm that may ensue as a result of the decision to donate.

Why assume patients who benefit from donating fresh embryos to research to relieve their feelings of indebtedness are exploited in the process? Surely, not all agreements that are born out of indebtedness are exploitative. We agree. But when feelings of indebtedness are morally inappropriate or unjust (as with patients who do not deserve to feel indebted), people

\footnotetext{
${ }^{41}$ Canadian Television Network (CTV) Local News, May 13 ${ }^{\text {th }}, 2006$.
} 
who take advantage of them to secure an agreement take unfair advantage of another's vulnerabilities. Some women may feel beholden enough to be willing to donate fresh embryos to research only because of an intense desire to reproduce that comes from an oppressed and coerced self-image. They were coerced into believing that they are not real women if they cannot reproduce. So a desire that is a product of coercion fuels their sense of indebtedness and explains why they donate. Here, they are taken advantage of in their vulnerable state of having internalized a social mandate of reproduction for women. They are exploited because the advantage taken is unfair. The only potential benefit they receive is relief from a sense of indebtedness that is not authentic to them anyway. As such, one could argue that the women receive no real benefit, while the researchers clearly benefit; and therefore, the agreements that the women make with them must be exploitative.

Donations of fresh embryos by women who are vulnerable in the above way are also not purely consensual. A coercive social structure that makes some women desperate when they discover that they are infertile or cannot reproduce with their partners is what ultimately explains why these women donate their fresh embryos to research. In accepting their donation, physicians and, in turn, researchers not only take unfair advantage of them in their vulnerable state, but also compromise their freedom.

Thus, exploitation combined with a certain form of coercion is a possible barrier to women autonomously donating their fresh embryos to research. This barrier adds another layer - on top of misunderstanding and other forms of coercion — to the difficulty involved in having women make informed, autonomous choices about donating excess fresh embryos to stem cell research.

THE POSSIBILITY OF AUTONOMOUS DONATION OF EXCESS FRESH EMBRYOS 
According to the Ethics Committee of the American Society for Reproductive Medicine, '[w]ithout evidence that fresh embryos are significantly preferable to frozen embryos for ES [embryonic stem] cell use, it is appropriate to use only spare embryos that have been frozen' ${ }^{42}$ At the present time, such evidence is definitely lacking; we do not know whether fresh embryos in general are better than frozen-thawed embryos for this purpose, although we do know that fresh embryos deemed unsuitable for transfer are worse than frozen-thawed embryos in this regard. ${ }^{43}$ From the perspective of evidence-based research therefore, only frozen-thawed embryos ought to be used for stem cell research. We have reached the same conclusion from an ethics perspective, and more particularly, from the perspective of patients. We have focused on donating fresh embryos suitable for transfer (i.e., "healthy" embryos) to stem cell research, and argued that such donations violate women's self- and other-regarding interests, and that profound barriers exist to women making these donations in an autonomous fashion.

One might object to our claims about autonomy and insist that some patients will not misunderstand, be coerced or be exploited and that these patients ought to have the opportunity to donate their fresh embryos to stem cell research (whether suitable or unsuitable for transfer), provided that they perceive donation to be in their interests. Our response to this objection is twofold. First, the prospects of being able to identify the few patients who either are not subject to the above barriers to autonomy or could overcome them are dim. Second, the objection assumes that patients expressly prefer to donate fresh rather than frozen embryos; yet there are no grounds for this assumption. In fact, it would be most unusual for women who are fully informed to have this preference, even if they were staunch supporters of embryonic stem cell

\footnotetext{
${ }^{42}$ Ethics Committee of the ASRM, op. cit. note 27.

${ }^{43}$ Sjögren et al, op. cit. note 7.
} 
research, given that the goals of stem cell research could be achieved without their fresh embryos and thus without them having to incur the possible additional harms associated with fresh embryo donation. Importantly, the claim that research goals could be achieved without using fresh embryos would continue to be true if it were shown that human embryonic stem cell derivation was more efficient when using fresh embryos. Sometimes the most efficient option is not the most ethically sound option.

In closing, others have acknowledged that the consent process for the donation of fresh embryos to research is complicated, ${ }^{44}$ but we go further in this paper and argue that the process is so fraught with difficulties that it simply ought not to take place. As we have shown, the barriers to autonomous decision-making are too severe; and, perhaps more importantly, fresh embryo donation is contrary to the interests of female infertility patients and furthers their oppression. Women's interests are best served and their autonomy best promoted if they have the time and distance from their IVF treatment that would allow them to reflect carefully on whether they want to donate excess embryos to research (as happens with the usual delay when patients donate frozen embryos to research). Studies show that with time and distance, women often withdraw prior consent to donating frozen embryos to research or simply do not give final consent to donation. This pattern creates an incentive for researchers to get access to fresh embryos before women can reflect and change their mind. But this pattern also speaks loudly against allowing or, worse, endorsing such a practice. We join others in insisting that final consent for donation to embryo research ought to be delayed 'until a significant time after IVF treatment', which would definitely preclude the donation of fresh embryos. ${ }^{45}$

\footnotetext{
${ }^{44}$ Greely, op. cit. note 8 .

45 Nisker et al., op. cit. note 28, pp. 907.
} 


\section{ACKNOWLEDGEMENTS}

Funding provided by the Canadian Institutes of Health Research. Thanks go to Bioethics for allowing us to reprint this article, which was previously published as "Donating Fresh Versus Frozen Embryos to Stem Cell Research: In Whose Interests" (Bioethics 21(9), 2007: 465-477). Thanks also go to Andrew Botterell, Jeff Nisker, and an anonymous reviewer for helpful comments on a draft of the paper, and to Stuart Newman for directing us towards scientific papers on the use of fresh or frozen embryos in stem cell research. 